before, and which awakes a longing for the Sabbath peace of unknown deserts and adventures in untraversed paths."

Not, however, until Teheran was passed does he reach: the desert with which the book mainly deals, and on which the traveller camped day after day for several months, excepting at the few oases. In these latter it was occasionally possible to camp under the palms, where "the singing birds which twittered during the day are silent. The jackals start a melancholy serenade, and the soft plaintive song of the desert vibrates through the night." These oases are not entirely pleasurable. They are infested, especially by three venomous creatures: (1) a deadly snake, (2) scorpions, black and white, and (3) a poisonous tarancula spider, which lives out in the desert, but is attracted by the light of the camp fires.
Tebbes, and Dr. Hedin supports Sir Henry Yule's view that the famous Venetian passed here by the direct caravan route between Kuch-benan and Tebbes, in preference to the more modern view of Colonel Skyes and others, that it was by Naibend. It is interesting also to find that Polo's description of this desert "is as correct now as in the year I272 A.D."

Dr. Hedin's alluring story of his exploration of great scientific interest and importance in itself, is also full of interest for the general reader as well. His numerous sketches and coloured illustrations are admirable and characteristic, but his photographs are exceptionally beautiful. They far surpass in artistic and technical excellence anything to be found in previous books on those regions. The publishers are to be congratulated on their splendid reproduction of these pictures, and on the attractive appearance gener-

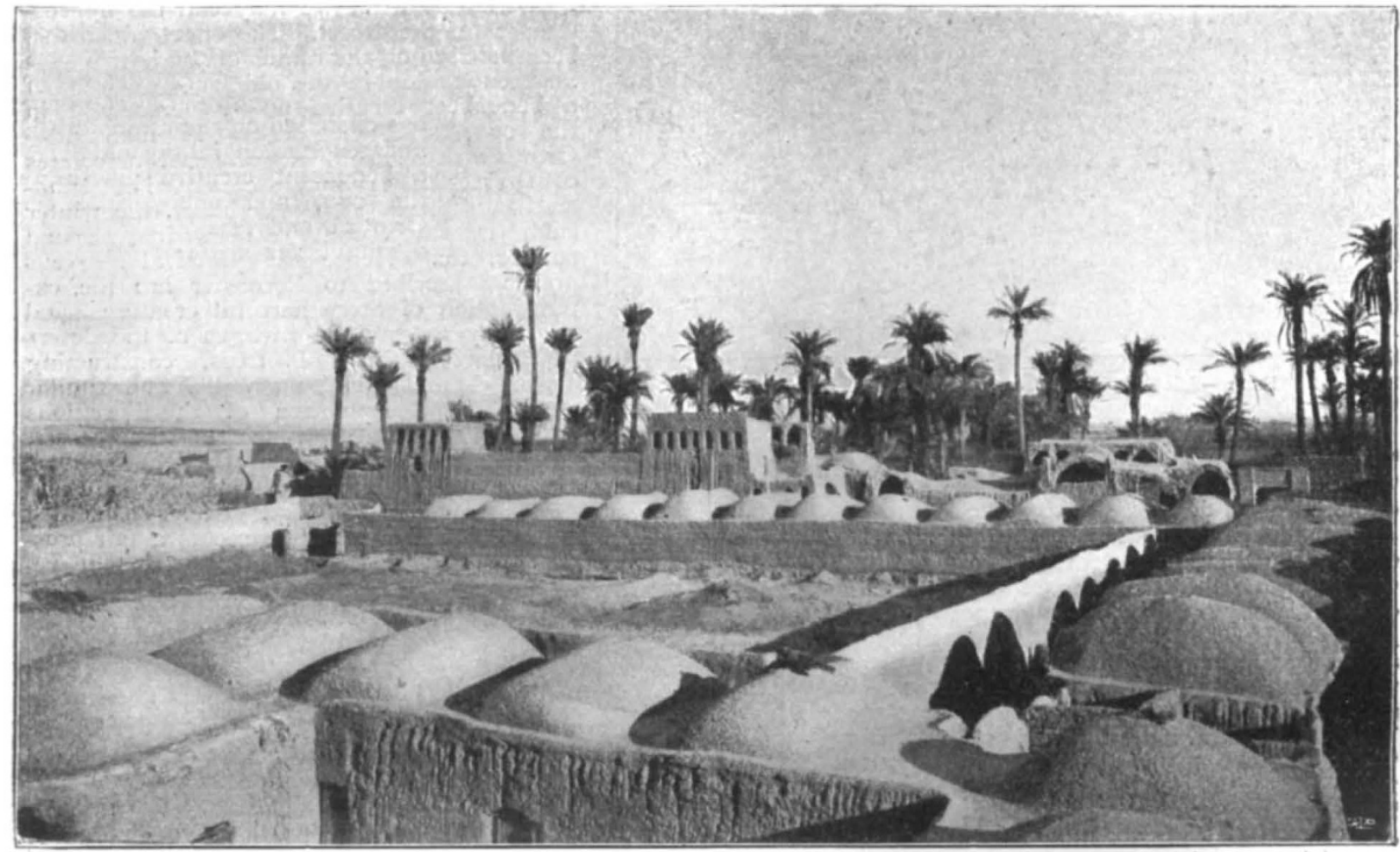

FIG. 3.-The Village of Chahrdeh. From "Overland to India."

Wolves levy a heavy tax upon the village flocks. Thev are individually so well known to the shepherds that each of them has received names, and their haunts are well known. They even attack the camels: "they leap on to the camel's back and crawl down to his neck and tear his throat." Although it was reported that wild camels existed, "no one had ever seen them."

The northern limit of the date palm was found at Tebbes. Beyond this no palm-groves are met with, only a few single specimens in well-protected sites. At Tebbes, where, as throughout southern Persia, the palm supplies the staple food and is otherwise of inestimable service to man, it was calculated that there were 100,000 of the female tree--the male palms are very much fewer in number, and are called "nehr," the same word which is used to denote a stallion camel.

Marco Polo is believed to have passed through No. 2 I62, VOL. 86$]$ ally of the book, which is certain to meet with a wide and hearty welcome.

\section{THE PROBLEM OF INDUSTRIAL TRAINING.}

DURING the last few years the feeling has been steadily growing that a large part of the money spent on elementary education is wasted for the want of a proper system of education in continuation schools, whether day or evening, which should prepare children for their future work. Unemployment, the decay of apprenticeship due to the changed conditions of labour, the increased number of occupations for boys and girls which lead to no definite future, and the bookish style of our elementary-school education, have been responsible for this feeling of unrest in the minds of all thinking persons. Some have suggested the reform of the elementary-school curriculum by making it more practical; others the rais- 
ing of the school age to sixteen. There is much to be said in favour of both suggestions, and indeed the former is essential; but those who have thought over the problem feel that the raising of the school age will provide no remedy unless what may be called post-elementary or secondary education is directed into channels which will lead up to and adequately prepare children for their future work, whether of a professional, commercial, or industrial character. For professional and commercial occupations ordinary education has done something, but not enough; but for industrial occupations very little has been done except by classes which have been attended by students after a break of two or three years, during which time they have forgotten much that they had learnt at school. The need for some reform in our educational work and for an extension of education in continuation schools has been pointed out in papers read at the British Association meetings, in reports by the British Science Guild and the Consultative Committee of the Board of Education, and at conferences of education authorities.

The resolutions passed and the opinions expressed at the recent conference held at the Guildhall (see NATURE, March 2, p. 3I), supported as they were by men and women representing all classes of the community, may be considered as evidence of a strong feeling that the time has come for some definite action to be taken. As an industrial nation we cannot afford to neglect the adequate preparation of our children for their future careers any longer.

Doubtless the commercial training required for professional or clerical occupations presents the least difficulty, because such training is more or less. intimately connected with an extension of the curricula of higher grade and secondary schools with a definite objective, and generally there is no opposition to such education. The problems connected with the training of those who will take up occupations of a manual or industrial description are more difficult. As soon as such training is talked about there appears to be a general, though erroneous, fear that such training implies definite trade training, and that the market will be flooded with skilled workers; but an inspection of the work and methods of the schools to which we refer later on will show that this is unfounded. The object of these schools is to prepare those boys and girls who intend to enter various trades, so that they will have an opportunity of becoming skilled all-round workers rather than one-branch hands. The changed conditions of manufacture make some system of preparation in schools and technical institutions an absolute necessity.

In any general scheme, local trade conditions will have to be taken into account by local education authorities in arranging the curricula and in selecting the children suitable for the various types of schools. The number of pupils attending the various types of schools will ultimately be regulated by the laws of supply and demand. The training for industrial or trade occupations, if it is to be successful, must be given in special schools, such as preparatory trade schools, schools of arts and crafts, or technical institutes; and the instruction, whilst not neglecting the general education of the pupils, must include sound preliminary training in the theory and practice of the trades, whether of an artistic, scientific, or mechanical character.

There must be no attempt in such schools to supersede the training of the workroom, workshop, or factory; their aim should be to provide an all-round acquaintance, both theoretical and practical, with the particular trade or group of trades which the pupils will enter, and so to make up in part for the loss of those opportunities of learning formerly provided by

$$
\text { NO. } 2 \text { I62, VOL. 86] }
$$

the apprenticeship system in various industrial occupations.

A good beginning has already been made in this direction in London by the trade schools for girls, and at the London. County Council schools and the Borough and Woolwich Polytechnics; there are similar opportunities for boys at the L.C.C. Paddington and Poplar Schools of Engineering, the Shoreditch Technical Institute for woodwork, the Borough Polytechnic Institute for engineering and metal trades, the Stanley School, the L.C.C. Central School of Arts and Crafts, and at the National Bakery and Confectionary School at the Borough Polytechnic Institute; there are others which might also be mentioned. There are also schools of various kinds in many of the principal towns of the country, such as Leeds, Liverpool, Bradford, and Wigan. In nearly all the schools mentioned the work is a full-time course, but railway companies and large employers of labour in various parts of the country have afforded facilities for their young workmen to attend classes for short periods in the daytime, to enable them to improve themselves both by study and practice in the trades in, which they are engaged. Some problems in boy-labour in Government departments are also receiving attention, though much remains to be done.

Without considerable elasticity, no scheme of industrial training in schools and institutes can be thoroughly successful or completely satisfy the industrial and commercial needs of a practical nation such as ours; such training must be post-elementary; that is, must come, not under the regulations governing elementary schools, but under those governing technical schools and institutes, as otherwise there is a danger of limitations in various directions; it may be trammelled by religious questions, by large classes, by rigidity of syllabuses, and will probably suffer from lack of freedom in the choosing. of suitable teachers for the work. The type of teachers employed in such schools is indeed one of the most important factors of success, and such teachers must be chosen rather for their special trade and workroom experience than for their academic qualifications. The cooperation of employers and foremen on advisory committees will also form an iniportant feature in the work.

In conclusion, it should be remembered that trade prospers only with a nation which has an adequate supply of technically trained skilled workers. It is generally believed by those who have paid attention to the subject, and it is the opinion of those who can speak with authority, that the trades in which we hold our own are those in which apprenticeship or its equivalent is not yet dead. As the opportunities for apprenticeship in various trades are becoming fewer and fewer, something in the way of a substitute is necessary, and this can be supplied by wise modification and extension of our educational system in the direction of industrial training.

C. T. Millis.

\section{DAYLIGHT SAVING?}

$\mathrm{N}$ the face of it, the proposed Daylight Saving Bill is distinctly good. For a certain season in the year the clerks in the City of London will get one more hour to spare before the sun goes down. As a result of this they will have more time for the enjoyment of fresh air, more time for outdoor amusements, more time to learn rifle shooting, gain more health, become happier men, and enjoy other benefits. If this is really the case, then the clerks in the west of England, who have for years and years enjoyed 33 per cent. more evening sun than those in the eastern counties, ought to exhibit at least some trace of the benefits which accrue from an extra dose of 